\author{
Dionísia Castro \\ Klara Slezakova \\ Maria Teresa Oliva-Teles \\ Cristina Delerue-Matos \\ Maria Conceição Alvim- \\ Ferraz \\ Simone Morais \\ Maria Carmo Pereira
}

\section{Analysis of polycyclic aromatic hydrocarbons in atmospheric particulate samples by microwave- assisted extraction and liquid chromatography}

\begin{abstract}
A methodology based on microwave-assisted extraction (MAE) and LC with fluorescence detection (FLD) was investigated for the efficient determination of 15 polycyclic aromatic hydrocarbons (PAHs) regarded as priority pollutants by the US Environmental Protection Agency and dibenzo(a,l)pyrene in atmospheric particulate samples. PAHs were successfully extracted from real outdoor particulate matter (PM) samples with recoveries ranging from $81.4 \pm 8.8$ to $112.0 \pm 1.1 \%$, for all the compounds except for naphthalene $(62.3 \pm 18.0 \%)$ and anthracene $(67.3 \pm 5.7 \%)$, under the optimum MAE conditions $\left(30.0 \mathrm{~mL}\right.$ of $\mathrm{ACN}$ for $20 \mathrm{~min}$ at $\left.110^{\circ} \mathrm{C}\right)$. No clean-up steps were necessary prior to LC analysis. LOQs ranging from $0.0054 \mathrm{ng} / \mathrm{m}^{3}$ for benzo(a)anthracene to $0.089 \mathrm{ng} / \mathrm{m}^{3}$ for naphthalene were reached. The validated MAE methodology was applied to the determination of PAHs from a set of real world PM samples collected in Oporto (north of Portugal). The sum of particulate-bound PAHs in outdoor PM ranged from 2.5 and $28 \mathrm{ng} / \mathrm{m}^{3}$.
\end{abstract}

Keywords: Atmospheric particulate samples / Liquid chromatography / Microwave-assisted extraction / PAHs / PM

\section{Introduction}

Polycyclic aromatic hydrocarbons (PAHs) are ubiquitous environmental pollutants [1] and some of them are human genotoxic carcinogens [2]. PAHs are produced mainly by high-temperature reactions, such as incomplete combustion and pyrolysis of fossil fuels and biomasses [3, 4]. Major sources of PAHs in urban areas include automobile traffic, domestic heating, thermal power stations, and industrial emissions [5]. After formation and emission, partition of these compounds between the gaseous phase and the atmospheric aerosols occurs. Their semi-volatile nature makes them highly mobile throughout the environment, with deposition and revolatilization process distributing them between air, water and soil. Some PAHs are subject to long-range

Abbreviations: ACN, acetonitrile; FLD, fluorescence detection; MAE, microwave-assisted extraction; PAHs, polycyclic aromatic hydrocarbons; PM, particulate matter; SRM, standard reference material transport through the atmosphere making them a transboundary environmental problem [1].

Particulate matter (PM), which is a mixture of suspended particles and aerosols, can lead to health problems and even premature mortality. Recent research studies seem to indicate that PM with aerodynamic diameter less than 10 micrometers $\left(\mathrm{PM}_{10}\right)$ are associated with respiratory responses and PM with aerodynamic diameter less than 2.5 micrometers $\left(\mathrm{PM}_{2.5}\right)$ mainly with cardiovascular diseases [6]. Nevertheless, it is not yet clear if it is the physical or the chemical PM characteristics, or both, that are responsible for these effects [6]. Most of the PAHs with low vapor pressure in the air are adsorbed onto PM [7].

Benzo(a)pyrene is the marker used for the carcinogenic risk of PAHs in ambient air [1]. Recently and with the aim of minimizing harmful effects on human health and the environment as a whole of airborne PAH, the European Union defined a target value for benzo(a)pyrene: $1 \mathrm{ng} / \mathrm{m}^{3}$ for the total content in the $\mathrm{PM}_{10}$ fraction averaged over a calendar year [1]. However, the suitability of benzo(a)pyrene as an indicator of carcinogenic PAHs has been questioned by new findings on the presence of more potent PAHs such as dibenzo(a,l)pyrene [8]. It has been estimated to have a carcinogenic potency that is approximately 100 times that of benzo(a)pyrene [9]. Until now, however, 
works that include the determination of dibenzo(a,1)pyrene in PM are limited [10].

The extraction of PAHs from atmospheric PM can be achieved with a number of established methods [11, 12]. Microwave-assisted extraction (MAE) provides a technique where compounds can be extracted selectively, in a relatively short period of time compared to conventional extraction methods and allows for an enhanced extraction yield for the more volatile compounds which normally require special and separate extraction methods $[13,14]$. This approach supports sustainable development as it permits the use of lower toxicity solvents, and requires less energy and solvent than conventional processes, while generating fewer wastes [14]. Several authors explored the possibility of utilizing MAE for the extraction of PAHs from environmental materials [15]. In this study, a systematic investigation on the application of MAE and LC with fluorescence detection (FLD) for the determination of 15 PAHs regarded as priority pollutants by the US Environmental Protection Agency (US EPA), and dibenzo(a,1)pyrene in airborne PM samples was performed. Comparing to previous related MAE works [1619], only environmental friendly solvents were tested, dibenzo(a,1)pyrene was studied and the parameters evaluated include the temperature instead of the microwave power. The power is less interesting to control since it depends on the number of samples to be extracted at one time and if it is not adjusted accordingly, different temperatures will be reached in each run compromising extraction efficiency (in modern apparatus 14-40 samples can be simultaneously extracted). Also, the developed procedure avoids the need for extract clean-up steps before instrumental analysis.

For this work, outdoor PM samples from Oporto (north of Portugal) were collected in PTFE membrane filters for sampling periods of 12 and $24 \mathrm{~h}$. Usually quartz or glass fiber filters are used but these filters require a preheating at $400^{\circ} \mathrm{C}$ for $24 \mathrm{~h}$ prior to use in order to reduce their water and organic matter blank values [19]. The PTFE filters do not require this pretreatment and are appropriate to PM sampling at a low air flow and sampling time.

\section{Material and methods}

\subsection{Sampling}

For MAE optimization studies, PM sampling was performed in the city of Oporto, north of Portugal, at one site directly influenced by traffic emissions. The collection of the different PM fractions was performed using TCR TECORA Bravo H2 constant flow samplers (with flow rate $2.3 \mathrm{~m}^{3} / \mathrm{h}$ ) combined with $\mathrm{PM}_{10}$ and $\mathrm{PM}_{2.5}$ EN LVS sampling heads in compliance with norm EN12341 [20] and no more than $24 \mathrm{~h}$ of sampling by each filter. The par- ticles were collected on PTFE membrane filters with $2 \mu \mathrm{m}$ porosity [20].

Samples were stored at $-20^{\circ} \mathrm{C}$ and were protected from light. Optimal conditions of MAE were applied to analysis of outdoor PM samples $\left(\mathrm{PM}_{10}\right.$ and $\left.\mathrm{PM}_{2.5}\right)$, collected under the same above conditions, from 17 to 25 February 2008 in Oporto (Portugal).

\subsection{Reagents and materials}

Certified "EPA 16 PAHs" standard mixture and an individual standard of dibenzo(a,1)pyrene (DB(a,1)P) $2000 \mu \mathrm{g} /$ $\mathrm{mL}$ were purchased from Supelco, Bellefonte, PA, USA. The certified standard mixture included naphthalene (Naph) $1000 \mu \mathrm{g} / \mathrm{mL}$, acenaphthylene (Aci) $2000 \mu \mathrm{g} / \mathrm{mL}$, acenaphthene (Ace) $1000 \mu \mathrm{g} / \mathrm{mL}$, fluorene (Flu) $199.9 \mu \mathrm{g} /$ $\mathrm{mL}$, phenanthrene (Phe) $99.8 \mu \mathrm{g} / \mathrm{mL}$, anthracene (Ant) $100.0 \mu \mathrm{g} / \mathrm{mL}$, fluoranthene (Fln) $200.1 \mu \mathrm{g} / \mathrm{mL}$, pyrene (Pyr) $99.9 \mu \mathrm{g} / \mathrm{mL}$, benzo(a)anthracene (B(a)A) $100.1 \mu \mathrm{g} / \mathrm{mL}$, chrysene (Chry) $100.0 \mu \mathrm{g} / \mathrm{mL}$, benzo(b)fluoranthene (B(b)Ft) $\quad 200.2 \mu \mathrm{g} / \mathrm{mL}$, benzo(k)fluoranthene (B(k)Ft) $99.9 \mu \mathrm{g} / \mathrm{mL}$, benzo(a)pyrene (B(a)P) $100.0 \mu \mathrm{g} / \mathrm{mL}$, dibenzo(a,h)anthracene (DB(a,h)A) $200.0 \mu \mathrm{g} / \mathrm{mL}$, benzo(g,h,i)perylene $(\mathrm{B}(\mathrm{g}, \mathrm{h}, \mathrm{i}) \mathrm{P}) 200.0 \mu \mathrm{g} / \mathrm{mL}$, and indeno(1,2,3-cd)pyrene (InP) $100.1 \mu \mathrm{g} / \mathrm{mL}$. Working mixed standard solutions containing all the PAHs were prepared by dilution of the stock solutions with $\mathrm{ACN}$ and stored at $-20^{\circ} \mathrm{C}$ in darkness to avoid volatilization and photodegradation.

The standard reference material (SRM) 1650b (diesel PM) was provided by the National Institute of Standards and Technology (NIST; Gaithersburg, MD, USA).

Acetone (purity 99.8\%; Riedel-de Haën, Seelze, Germany), ACN Lichrosol for gradient elution (purity $>99.9 \%$ Carlo Erba, Rodano, Italy), methanol Lichrosol. For gradient elution (purity 99.9\%; Riedel-de Haën) and $n$-hexane Chromasolv (Merck, Darmstadt, Germany) were used.

Ultra-pure water was prepared by a Milli-Q simplicity 185 system (Millipore, Molsheim, France).

The glassware was washed with detergent and water, rinsed with acetone and $n$-hexane and dried at $90^{\circ} \mathrm{C}$ before use.

\subsection{Microwave-assisted extraction}

MAE experiments were performed with a MARS-X $1500 \mathrm{~W}$ Microwave Accelerated Reaction System for Extraction and Digestion (CEM, Mathews, NC, USA) configured with a 14 position carousel. During operation, both temperature and pressure were monitored in a single vessel. Magnetic stirring in each extraction vessel and a sensor registering the solvent leaks in the interior of the microwave oven were also used.

For optimization studies, each membrane filter after sampling was cut into two parts having, as much as possible, the same size which were accurately weighted. One 
Table 1. Spiking range tested for each $\mathrm{PAH}$

\begin{tabular}{ll}
\hline Compound & Spiking range $(\mu \mathrm{g} / \mathrm{g})^{\mathrm{a})}$ \\
\hline Naphthalene & $0.916-2.05$ \\
Acenaphthene & $1.07-2.63$ \\
Fluorene & $0.196-0.420$ \\
Phenanthrene & $0.110-0.232$ \\
Anthracene & $0.123-0.225$ \\
Fluoranthene & $0.227-0.268$ \\
Pyrene & $0.101-0.218$ \\
Benzo(a)anthracene & $0.109-0.226$ \\
Chrysene & $0.112-0.230$ \\
Benzo(b)fluoranthene & $0.224-0.487$ \\
Benzo(k)fluoranthene & $0.120-0.229$ \\
Benzo(a)pyrene & $0.121-0.232$ \\
Dibenzo(a,1)pyrene & $0.212-0.538$ \\
Dibenzo(a,h)anthracene & $0.215-0.444$ \\
Benzo(g,h,i)perylene & $0.106-0.250$ \\
Indeno(1,2,3-cd)pyrene & $0.045-0.192$ \\
\hline
\end{tabular}

a) The spiking level was calculated as $\mu \mathrm{g}$ of $\mathrm{PAH}$ per mass of particulate matter and filter.

half of the filter was analyzed without fortification (blank), and the other one was spiked with the standard solution mixture containing the 16 selected PAHs at levels ranging from $0.045 \mu \mathrm{g} / \mathrm{g}$ for indeno(1,2,3-cd)pyrene to $2.63 \mu \mathrm{g} / \mathrm{g}$ for acenaphthene (Table 1). Spiked samples were allowed to stand for $30 \mathrm{~min}$ before extraction. Spiked and nonspiked (blank) PTFE filters containing PM were transferred to the glass extraction vessels. After adding to each sample $30.0 \mathrm{~mL}$ of the selected MAE solvent, the vessels were closed. Three solvents and four extraction temperatures were tested, namely, hexane/acetone $(1: 1 \mathrm{v} / \mathrm{v}), \mathrm{ACN}(100 \%)$ and ultra-pure water $(100 \%)$ at 90 , 100,110 , and $120^{\circ} \mathrm{C}$. Using the optimum solvent and temperature, extraction time was varied during 5,10 , 15 , and $20 \mathrm{~min}$.

After MAE, the vessels were allowed to cool at room temperature before opening. The extracts were then carefully filtered through a PTFE membrane filter $(0.45 \mu \mathrm{m})$ and reduced to a small volume using a rotary evaporator (Buchi Rotavapor, R-200) at $20^{\circ} \mathrm{C}$. Then, a gentle stream of nitrogen was used to evaporate the extracts and immediately before chromatographic analysis, the residue was redissolved in $1000 \mu \mathrm{L}$ of ACN.

To evaluate the extraction efficiency, recoveries were calculated after correction for the blank contribution.

\subsection{Chromatographic analysis}

The extracts were analyzed using a Shimadzu LC system equipped with an LC-20AD pump, a DGU-20AS degasser and a fluorescence RF-10AXL detector. The chromatographic separations were carried out using an MP-PAH C18 (YMC) column ( $50 \mathrm{~mm} \times 4.0 \mathrm{~mm}$; $3 \mu \mathrm{m}$ particle size). The injected volume was $15.0 \mu \mathrm{L}$. A water/ACN mixture was used as the mobile phase and different solvent gradient programs were tested to reduce the analysis time while keeping a good resolution of all PAHs studied. The following chromatographic conditions were selected: initial conditions 45:55 ACN/water, then a linear ramp to $100 \%$ ACN in $15 \mathrm{~min}$, holding this condition during $7 \mathrm{~min}$. The flow rate was $0.8 \mathrm{~mL} / \mathrm{min}$.

The FLD was optimized for each PAH to obtain a good sensitivity and minimal interferences. The excitation/ emission wavelength pair of 260/315 nm was selected for initial time, at $8.0 \mathrm{~min}$ it was changed to $260 / 366 \mathrm{~nm}$, at $9.0 \mathrm{~min}$ to $260 / 430 \mathrm{~nm}$ and at $18.8 \mathrm{~min}$ to $290 / 505 \mathrm{~nm}$. Acenaphthylene determination was not performed due to its absence of fluorescence.

\section{Results and discussion}

\subsection{Chromatographic analysis}

The purpose of this study was to develop a simple and robust method based on MAE and LC-FLD for the determination of 16 PAHs in atmospheric particulate samples. The optimized chromatographic program allowed an efficient separation and quantification of the studied compounds in only $20 \mathrm{~min}$ as it can be observed in Fig. 1.

The linearity range, LOD, LOQ, and quadratic correlation coefficients $\left(R^{2}\right)$ for each PAH are shown in Table 2. Calibration curves obtained using six mixed standard solutions containing all the PAHs showed good linearity over the entire range of concentrations with quadratic correlation coefficients $\left(R^{2}\right)$ of 0.9999. LODs and LOQs were calculated expressed as PAH concentration in solution $(\mu \mathrm{g} / \mathrm{L})[21]$ and in air samples for a flow rate of $2.3 \mathrm{~m}^{3}$ | $\mathrm{h}$, during $24 \mathrm{~h}$, which were the conditions employed throughout the present study. LODs between $0.0016 \mathrm{ng} /$ $\mathrm{m}^{3}(0.090 \mu \mathrm{g} / \mathrm{L})$ for benzo(a)anthracene and $0.027 \mathrm{ng} / \mathrm{m}^{3}$ $(1.5 \mu \mathrm{g} / \mathrm{L})$ for naphthalene were obtained, with corresponding LOQs in the range of $0.0054-0.089 \mathrm{ng} / \mathrm{m}^{3}$ $(0.30-4.90 \mu \mathrm{g} / \mathrm{L})$.

In contrast to previous published studies [15-18], clean-up of MAE extracts was not found to be necessary.

\subsection{Optimization of MAE procedure}

To fully understand the way in which MAE critical variables affect PAHs extraction yields, three parameters were considered: solvent, temperature, and extraction time. The stirring speed (medium; Gfrerer and Lankmayr concluded that stirring during MAE was essential [22]) and solvent volume (the membrane should be completely submerged in the solvent; thus $30.0 \mathrm{~mL}$ of solvent are required) were kept constant.

Considering the selection of solvent, hexane-acetone mixtures, toluene, methylene chloride, benzene, and dichloromethane are known to be good solvents for 


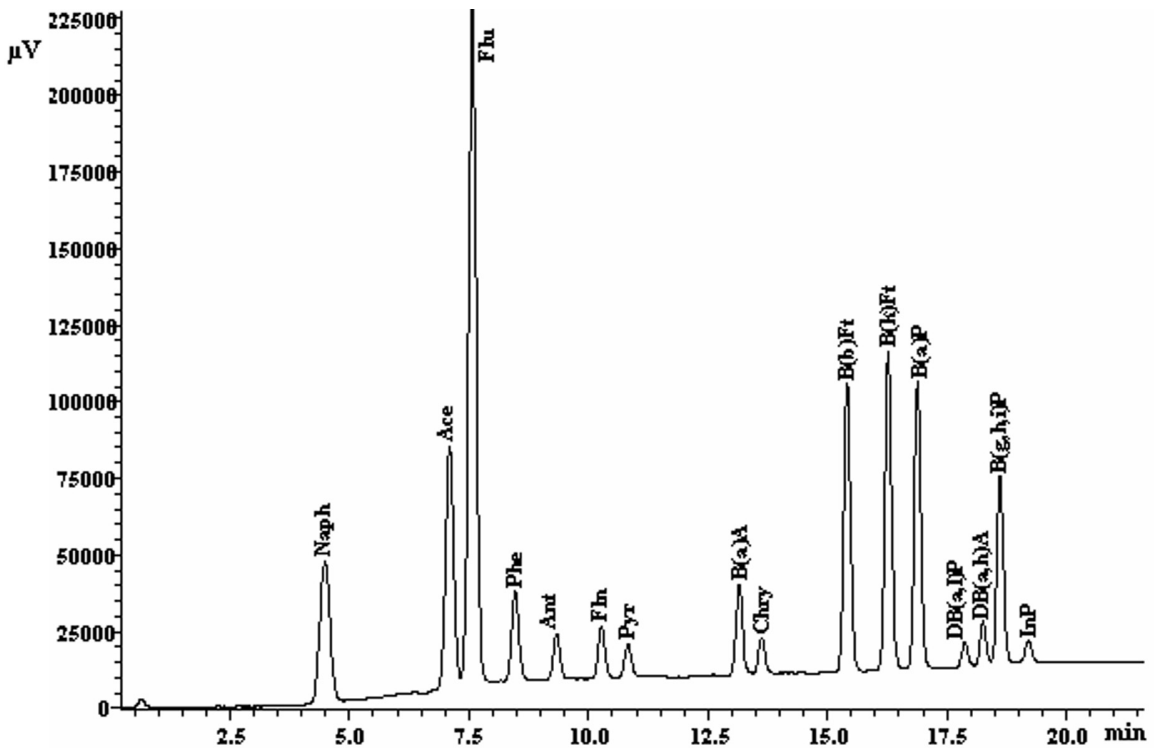

Figure 1. LC-FLD chromatogram of a standard PAHs mixture containing 16 PAHs (Naph, $100 \mu \mathrm{g} / \mathrm{L}$; Ace, $100 \mu \mathrm{g} / \mathrm{L} ;$ Flu, $19.8 \mu \mathrm{g} / \mathrm{L} ;$ Phe, $10.0 \mu \mathrm{g} / \mathrm{L} ;$ Ant, $10.0 \mu \mathrm{g} / \mathrm{L}$, FIn, $19.7 \mu \mathrm{g} / \mathrm{L} ; \mathrm{Pyr}, 9.69 \mu \mathrm{g} / \mathrm{L} ; \mathrm{B}(\mathrm{a}) \mathrm{A}$, $9.84 \mu \mathrm{g} / \mathrm{L} ;$ Chry, $9.91 \mu \mathrm{g} / \mathrm{L} ; \mathrm{B}(\mathrm{b}) \mathrm{Ft}$, $20.0 \mu \mathrm{g} / \mathrm{L} ; \mathrm{B}(\mathrm{k}) \mathrm{Ft}, 9.98 \mu \mathrm{g} / \mathrm{L}$; $\mathrm{B}(\mathrm{a}) \mathrm{P}, 10.0 \mu \mathrm{g} / \mathrm{L} ; \mathrm{DB}(\mathrm{a}, \mathrm{I}) \mathrm{P}$, $20.0 \mu \mathrm{g} / \mathrm{L} ; \mathrm{DB}(\mathrm{a}, \mathrm{h}) \mathrm{A}, 20.0 \mu \mathrm{g} / \mathrm{L}$; $\mathrm{B}(\mathrm{g}, \mathrm{h}, \mathrm{i}) \mathrm{P}, 19.9 \mu \mathrm{g} / \mathrm{L}$; and $\mathrm{InP}$, $10.0 \mu \mathrm{g} / \mathrm{L})$.

Table 2. Average retention time and calibration data for the selected PAHs

\begin{tabular}{|c|c|c|c|c|c|c|c|c|}
\hline Compound & $\begin{array}{l}\text { Retention } \\
\text { time (min) }\end{array}$ & $\begin{array}{l}\text { Calibration } \\
\text { range }(\mu \mathrm{g} / \mathrm{L} ; \\
n=6)\end{array}$ & $\begin{array}{l}\text { Regression equation } \\
(n=6)\end{array}$ & & $\begin{array}{l}\text { LOD } \\
(\mu g / L)\end{array}$ & $\begin{array}{l}\mathrm{LOD}^{\mathrm{b})} \\
\left(\mathrm{ng} / \mathrm{m}^{3}\right)\end{array}$ & $\begin{array}{l}\mathrm{LOQ} \\
(\mu \mathrm{g} / \mathrm{L})\end{array}$ & $\begin{array}{l}\mathrm{LOQ}^{\mathrm{b})} \\
\left(\mathrm{ng} / \mathrm{m}^{3}\right)\end{array}$ \\
\hline Naphthalene & 4.3 & $2.5-200.6$ & $y=6076 x+7276$ & 0.9999 & 1.5 & 0.027 & 4.9 & 0.089 \\
\hline Acenaphthene & 6.9 & $2.5-200.6$ & $y=700 x-2957$ & 0.9999 & 0.81 & 0.015 & 2.7 & 0.049 \\
\hline Fluorene & 7.4 & $0.50-39.6$ & $y=102856 x+6716$ & 0.9999 & 0.12 & 0.0022 & 0.40 & 0.0072 \\
\hline Phenanthrene & 8.2 & $0.25-20.0$ & $y=26569 x+6233$ & 0.9999 & 0.27 & 0.0049 & 0.89 & 0.016 \\
\hline Anthracene & 9.1 & $0.25-20.0$ & $y=11774 x-524$ & 0.9999 & 0.48 & 0.0087 & 1.6 & 0.029 \\
\hline Fluoranthene & 10.0 & $2.5-39.5$ & $y=7322 x-647$ & 0.9999 & 0.19 & 0.0034 & 0.63 & 0.011 \\
\hline Pyrene & 10.6 & $1.2-19.4$ & $y=9045 x-668$ & 0.9999 & 0.19 & 0.0034 & 0.66 & 0.012 \\
\hline Benzo(a)anthracene & 12.9 & $0.25-19.7$ & $y=22686 x-3894$ & 0.9999 & 0.09 & 0.0016 & 0.30 & 0.0054 \\
\hline Chrysene & 13.4 & $0.50-19.8$ & $y=8317 x-3810$ & 0.9999 & 0.26 & 0.0047 & 0.88 & 0.016 \\
\hline Benzo(b)fluoranthene & 15.2 & $0.50-40.2$ & $y=39620 x-3169$ & 0.9999 & 0.24 & 0.0043 & 0.80 & 0.014 \\
\hline Benzo(k)fluoranthene & 16.0 & $0.25-19.9$ & $y=86758 x-4520$ & 0.9999 & 0.11 & 0.0020 & 0.36 & 0.0065 \\
\hline Benzo(a)pyrene & 16.7 & $0.25-20.1$ & $y=75249 x+2243$ & 0.9999 & 0.16 & 0.0029 & 0.54 & 0.0098 \\
\hline Dibenzo(a,h)anthracene & 18.1 & $1.0-15.0$ & $y=2577 x-1330$ & 0.9999 & 0.37 & 0.0067 & 1.2 & 0.022 \\
\hline Benzo(g,h,i)perylene & 18.4 & $0.99-29.8$ & $y=22521 x-14665$ & 0.9999 & 0.21 & 0.0038 & 0.70 & 0.013 \\
\hline Indeno( $1,2,3$-cd)pyrene & 19.0 & $0.25-10.0$ & $y=5304 x-765$ & 0.9999 & 0.35 & 0.0063 & 1.2 & 0.022 \\
\hline
\end{tabular}

a) $y$, area; $x$, concentration $(\mu \mathrm{g} / \mathrm{L})$.

b) LOD and LOQ were expressed as PAH concentration in air for a flow rate of $2.3 \mathrm{~m}^{3} / \mathrm{h}$, during $24 \mathrm{~h}$.

PAHs extractions and are commonly used worldwide although some are highly toxic and should be slowly being phased out from analytical methods [19, 23-29]. In this study, only solvents presenting low toxicity were tested. When considering MAE, due to the principle of microwave heating, the choice of the solvent depends on its ability to absorb microwaves, defined by its dielectric constant $\left(\varepsilon^{\prime}\right)$. Apolar solvents such as hexane do not meet this requirement and despite the fact that they are known to be appropriate for aromatic compounds they cannot be used alone. On the other hand, only a few works were devoted to find a suitable solvent for the MAE of PAHs from airborne [19] and diesel [30] PM. In this study, for selection of the optimum MAE solvent, extraction efficiency was evaluated testing three solvents, namely, hexane/acetone $(1: 1 \mathrm{v} / \mathrm{v}), \mathrm{ACN}$ and ultrapure water using spiked samples containing all the PAHs.

The solvent mixture hexane/acetone $(1: 1 \mathrm{v} / \mathrm{v})$ was included since it has proven to be an efficient solvent system for the extraction of different pollutants from environmental samples such as PAHs, organochlorine pesticides, PCBs, phenols, and organophosphorus pesticides [31].

ACN was selected to be tested as extraction solvent since it is compatible with the optimized LC-FLD procedure and consequently, no solvent exchange is required 
to reduce the loss of analytes during sample preparation. This is particularly important for PAHs since, some of these compounds are extremely volatile and if, during an evaporation step, the extract is taken to complete dryness, naphthalene, acenaphthene, and fluorene can be totally lost [32]. Also, none of the previous works related with PAHs MAE tested it as solvent and ACN has a higher dielectric constant than acetone which is commonly used $\left(\varepsilon_{\text {ACN }}^{\prime}=35.9, \varepsilon_{\text {acetone }}^{\prime}=20.7\right.$ at $25^{\circ} \mathrm{C}$ [33]).

Water was included since PAHs represent a group of pollutants which include a great range of vapor pressures and water solubilities (as well as solubilities in extraction solvents) [34, 35]. Thus, PAHs might be expected to show a wide range of extraction behavior.

According to the literature, only one study was carried out on the influence of the temperature on extractability of PAHs by MAE from diesel PM [30]. In this previous study, methylene chloride, THF, and chloroform were tested for $37 \mathrm{~min}$ at $80,95,110,125$, and $140^{\circ} \mathrm{C}$. At high temperatures, the rate of extraction increases because the viscosity and the surface tension decreases, while solubility and diffusion rate into the sample increase. However, draconian extraction conditions (high temperature and pressure) usually affect negatively the extraction selectivity and vigorous cleaning steps are required before the analysis [13]. In our work the three solvents selected were tested at $90,100,110$, and $120^{\circ} \mathrm{C}$. Figure 2 shows the recovery data obtained after 20 min of extraction. The fortification range used, calculated as mass of PAH per mass of PM and filter, are shown in Table 1.

Hexane/acetone $(1: 1 \mathrm{v} / \mathrm{v})$ and ACN allow the extraction of all compounds over the entire range of temperatures studied. Considering the 16 PAHs altogether, it can be seen that the highest results were obtained at $110^{\circ} \mathrm{C}$. The mixture of hexane-acetone (Fig. 2a) provided overall average recoveries of $66.9 \pm 9.7,63.1 \pm 10,84.6 \pm 6.0$, and $50.1 \pm 9.5 \%$ at $90,100,110$, and $120^{\circ} \mathrm{C}$, respectively. For anthracene, fluoranthene, and pyrene, a lower temperature of $90-100^{\circ} \mathrm{C}$ seemed to be more appropriate. Using $\mathrm{ACN}$ and at all the temperatures tested (Fig. 2b), higher overall average results were reached when compared with those of hexane/acetone $(1: 1 \mathrm{v} / \mathrm{v})$, namely, $74.6 \pm 8.4$, $72.0 \pm 8.1,90.5 \pm 5.9$, and $68.9 \pm 5.8 \%$ at $90,100,110$, and $120^{\circ} \mathrm{C}$, respectively. The four PAHs which have lower retention time and boiling point, i.e., naphthalene, acenaphthene, fluorene, and phenanthrene, are the most affected by the variation of temperature. All analytes are acceptably extracted at $110^{\circ} \mathrm{C}$ with ACN. The recoveries of all the targeted contaminants were in the range of $81.4 \pm 8.8-112.0 \pm 1.1 \%$ except for naphthalene $(62.3 \pm$ $18.0 \%)$ and anthracene $(67.3 \pm 5.7 \%)$ (Fig. 2b). On the other hand, at the optimum extraction temperature $\left(110^{\circ} \mathrm{C}\right)$ for the mixture hexane/acetone $(1: 1 \mathrm{v} / \mathrm{v})$, recovery values lower than $\mathrm{ca} .70 \%$ were obtained for naphthalene $(41.0 \pm 14.0 \%)$, acenaphthene $(62.4 \pm 5.1 \%)$, phenanthrene (56.7 $\pm 2.1 \%)$, and anthracene $(21.3 \pm 1.1 \%)$ (Fig. $2 \mathrm{a})$.

When extractions were performed with water (Fig. 2c), and although naphthalene, acenaphthene, fluorene, and phenanthrene have water solubility higher than $1 \mathrm{mg} / \mathrm{L}$ (32, 4, 2, and 1.3, respectively) [34], the first seven PAHs were not detected and for the other analytes very poor recoveries ( $3 \%$ for benzo(a)anthracene to 35\% for dibenzo(a,1)pyrene) were attained.

Taking all these observations into consideration, the chosen solvent was ACN at $110^{\circ} \mathrm{C}$. Then, the influence of the extraction time on the recovery of the selected group

Table 3. Recoveries obtained from $P M$ samples $\left(\mathrm{PM}_{10}\right)$ using $\mathrm{ACN}$ as extraction solvent at $110^{\circ} \mathrm{C}$ during several extraction times

\begin{tabular}{|c|c|c|c|c|}
\hline \multirow[t]{2}{*}{ Compound } & \multicolumn{4}{|c|}{ Recovery \pm RSD $(\% ; n=3)$} \\
\hline & $5 \mathrm{~min}$ & $10 \mathrm{~min}$ & $15 \min$ & $20 \mathrm{~min}$ \\
\hline Naphthalene & $9.90 \pm 0.50$ & $13.9 \pm 13.0$ & $23.6 \pm 5.0$ & $62.3 \pm 18.0$ \\
\hline Acenaphthene & $52.8 \pm 17.0$ & $74.3 \pm 2.3$ & $84.6 \pm 0.7$ & $100.0 \pm 2.3$ \\
\hline Fluorene & $78.8 \pm 15.0$ & $87.1 \pm 2.3$ & $108.0 \pm 7.8$ & $112.0 \pm 1.1$ \\
\hline Phenanthrene & $79.6 \pm 11.0$ & $85.9 \pm 13$ & $101.0 \pm 2.0$ & $89.0 \pm 19.0$ \\
\hline Anthracene & $48.0 \pm 4.8$ & $58.9 \pm 2.0$ & $74.7 \pm 4.4$ & $67.3 \pm 5.7$ \\
\hline Fluoranthene & $62.3 \pm 9.7$ & $102.0 \pm 3.5$ & $124 \pm 2.7$ & $81.4 \pm 8.8$ \\
\hline Pyrene & $96.2 \pm 0.8$ & $90.3 \pm 4.6$ & $91.4 \pm 8.4$ & $90.6 \pm 5.5$ \\
\hline Benzo(a)anthracene & $95.1 \pm 14.0$ & $99.5 \pm 5.0$ & $106.5 \pm 1.4$ & $90.8 \pm 7.5$ \\
\hline Chrysene & $104.0 \pm 4.8$ & $101.0 \pm 4.4$ & $103.0 \pm 2.2$ & $90.4 \pm 6.3$ \\
\hline Benzo(b)fluoranthene & $80.9 \pm 13$ & $112.0 \pm 1.8$ & $85.7 \pm 5.0$ & $97.1 \pm 2.1$ \\
\hline Benzo(k)fluoranthene & $98.0 \pm 5.4$ & $106.0 \pm 3.6$ & $104.0 \pm 3.2$ & $97.0 \pm 1.9$ \\
\hline Benzo(a)pyrene & $78.7 \pm 8.3$ & $102.0 \pm 3.4$ & $87.6 \pm 10$ & $93.6 \pm 2.8$ \\
\hline Dibenzo(a,l)pyrene & $97.0 \pm 5.9$ & $92.1 \pm 1.8$ & $98.9 \pm 3.1$ & $93.1 \pm 5.6$ \\
\hline Dibenzo(a,h)anthracene & $57.1 \pm 8.7$ & $68.4 \pm 5.3$ & $94.5 \pm 3.7$ & $91.1 \pm 2.7$ \\
\hline Benzo(g,h,i)perylene & $91.7 \pm 3.9$ & $107.0 \pm 0.8$ & $90.5 \pm 12.0$ & $95.2 \pm 1.2$ \\
\hline Indeno(1,2,3-cd)pyrene & $67.6 \pm 16$ & $69.5 \pm 1.4$ & $99.1 \pm 8.6$ & $96.4 \pm 3.6$ \\
\hline
\end{tabular}

$n$, Number of samples. 

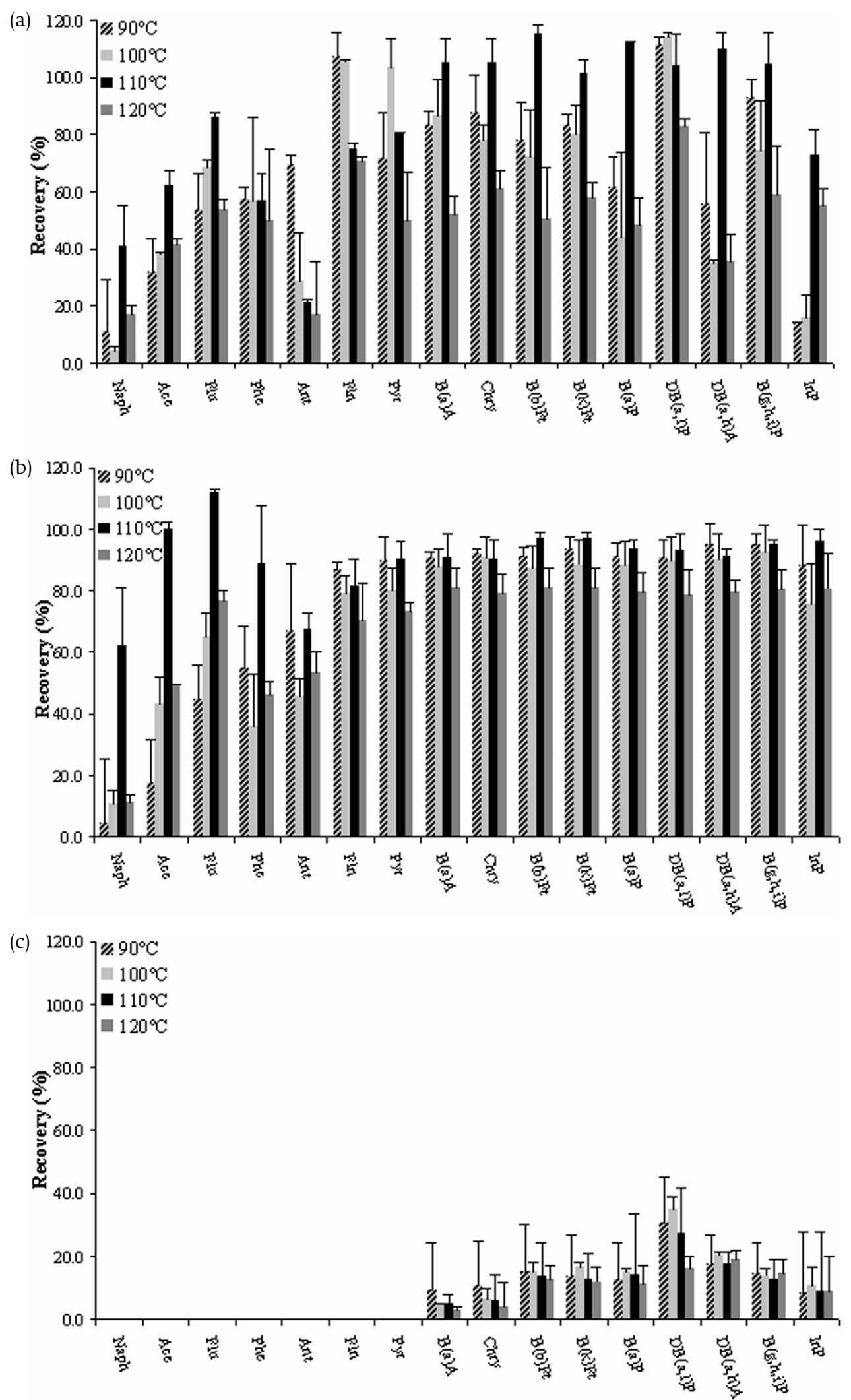

Figure 2. Effect of solvent and temperature on MAE of the studied PAHs: (a) hexane/acetone (1:1 v/v); (b) ACN, and (c) water. The fortification range used, calculated as mass of PAH per mass of PM and filter, is shown in Table 1 . Bars correspond to mean $\pm \operatorname{RSD}(n=3)$. 
Table 4. Recoveries obtained with the optimal extraction conditions for PM samples having different sizes $\left(\mathrm{PM}_{10}\right.$ and $\mathrm{PM}_{2.5}$ )

\begin{tabular}{|c|c|c|}
\hline \multirow[t]{2}{*}{ Compound } & \multicolumn{2}{|c|}{ Recovery $\pm \operatorname{RSD}(\% ; n=3)$} \\
\hline & $\mathrm{PM}_{2.5}$ & $\mathrm{PM}_{10}$ \\
\hline Naphthalene & $56.7 \pm 9.1$ & $62.3 \pm 18.0$ \\
\hline Acenaphthene & $88.5 \pm 3.2$ & $100.0 \pm 2.3$ \\
\hline Fluorene & $98.2 \pm 3.9$ & $112.0 \pm 1.1$ \\
\hline Phenanthrene & $101.0 \pm 4.7$ & $89.0 \pm 19.0$ \\
\hline Anthracene & $66.7 \pm 7.2$ & $67.3 \pm 5.7$ \\
\hline Fluoranthene & $84.2 \pm 5.5$ & $81.4 \pm 8.8$ \\
\hline Pyrene & $87.5 \pm 4.7$ & $90.6 \pm 5.5$ \\
\hline Benzo(a)anthracene & $82.8 \pm 4.5$ & $90.8 \pm 7.5$ \\
\hline Chrysene & $86.3 \pm 3.3$ & $90.4 \pm 6.3$ \\
\hline Benzo(b)fluoranthene & $88.6 \pm 5.7$ & $97.1 \pm 2.1$ \\
\hline Benzo(k)fluoranthene & $88.6 \pm 4.6$ & $97.0 \pm 1.9$ \\
\hline Benzo(a)pyrene & $90.4 \pm 2.7$ & $93.6 \pm 2.8$ \\
\hline Dibenzo(a,l)pyrene & $90.5 \pm 1.8$ & $93.1 \pm 5.6$ \\
\hline Dibenzo(a,h)anthracene & $96.4 \pm 2.1$ & $91.1 \pm 2.7$ \\
\hline Benzo(g,h,i)perylene & $86.5 \pm 2.6$ & $95.2 \pm 1.2$ \\
\hline Indeno(1,2,3-cd)pyrene & $95.2 \pm 3.2$ & $96.4 \pm 3.6$ \\
\hline
\end{tabular}

$n$, Number of samples.

of PAHs was examined. Mass transfer is a time dependent process and, as it can be seen from Table 3, extraction times in the range of 5-15 min lead to an increase in extraction efficiency whereas with a further prolongation of extraction time (15-20 min) no significant effect was observed for most compounds except for naphthalene, acenaphthene, and fluoranthene. The overall mean recoveries obtained at $5,10,15$, and $20 \mathrm{~min}$ were $74.9 \pm 8.7,85.5 \pm 4.3,92.3 \pm 5.0$, and $90.5 \pm 5.9 \%$, respec- tively. Although the extraction time of 15 min provided the maximum global value, the recovery reached using 20 min for naphthalene, which is the PAH more difficult to extract, was significantly higher and in agreement with other authors that applied other extraction techniques [36, 37]. Therefore, and since acceptable recoveries for the remaining compounds were attained, $20 \mathrm{~min}$ was selected as optimal time. Moreover, this extraction time is short especially when compared to the duration of the traditional Soxhlet process.

As the size of the particles could affect the extraction of PAHs, the optimum conditions of MAE for $\mathrm{PM}_{10}$ (30.0 $\mathrm{mL} \mathrm{ACN}$ at $110^{\circ} \mathrm{C}$ during $20 \mathrm{~min}$ ) were applied to $\mathrm{PM}_{2.5}$ ("respirable" particles that can penetrate into the gas-exchange region of the lung [6]). The results obtained are showed in Table 4. Statistical analysis was carried out on the analytes investigated using a nonparametric test (Mann-Whitney) at 95\% confidence level [38]. No significant differences $(p>0.05)$ were found in PAH extraction efficiency between both sizes of PM.

Table 5 summarizes the data obtained for the MAE of the studied group of PAHs from SRM 1650b "Diesel particulate matter" (only dibenzo(a,l)pyrene is not present). This material is the representative of heavy duty diesel emissions and it was certified for all analyzed compounds except for acenaphthene and fluorene. Quantitative extraction $(>72 \%)$ succeeded for eight PAHs. For the nine compounds with lower retention times (naphthalene, acenaphthene, fluorene, phenanthrene, anthracene, fluoranthene, pyrene, benzo(a)anthracene, and chrysene) similar recoveries as those reached with PM samples were attained validating the developed proce-

Table 5. Certified, reference (noncertified) and measured concentrations of native PAHs (mean, SD, and RSD) in the NIST reference material SRM $1650 \mathrm{~b}(n=4)$

\begin{tabular}{|c|c|c|c|}
\hline \multirow[t]{2}{*}{ Compound } & \multicolumn{3}{|c|}{ Mass fraction, mean $\pm \mathrm{SD}(\mu \mathrm{g} / \mathrm{g})$} \\
\hline & $\begin{array}{l}\text { Certified or reference } \\
\text { values }\end{array}$ & Measured values & Recovery $\pm \operatorname{RSD}(\%)$ \\
\hline Naphthalene & $5.07 \pm 0.40^{\mathrm{a})}$ & $2.35 \pm 0.26$ & $46.3 \pm 9.4$ \\
\hline Acenaphthene & $0.223 \pm 0.020^{\mathrm{b})}$ & $0.220 \pm 0.020$ & $98.3 \pm 6.9$ \\
\hline Fluorene & $1.26 \pm 0.090^{\mathrm{b})}$ & $1.16 \pm 0.09$ & $92.4 \pm 5.8$ \\
\hline Phenanthrene & $69.5 \pm 1.9^{\mathrm{a})}$ & $57.8 \pm 4.1$ & $83.2 \pm 5.3$ \\
\hline Anthracene & $7.67 \pm 0.47^{\mathrm{a})}$ & $5.51 \pm 0.65$ & $71.8 \pm 8.2$ \\
\hline Fluoranthene & $47.3 \pm 0.80^{\mathrm{a})}$ & $43.8 \pm 2.0$ & $92.6 \pm 3.4$ \\
\hline Pyrene & $43.4 \pm 1.6^{\mathrm{a})}$ & $42.1 \pm 4.0$ & $97.1 \pm 6.9$ \\
\hline Benzo(a)anthracene & $6.18 \pm 0.30^{\mathrm{a})}$ & $5.96 \pm 0.38$ & $96.4 \pm 5.1$ \\
\hline Chrysene & $13.3 \pm 1.1^{\mathrm{a})}$ & $11.5 \pm 0.6$ & $86.2 \pm 4.4$ \\
\hline Benzo(b)fluoranthene & $6.77 \pm 0.84^{\mathrm{a})}$ & $1.41 \pm 0.24$ & $20.9 \pm 13.0$ \\
\hline Benzo(k)fluoranthene & $2.37 \pm 0.21^{\mathrm{a})}$ & $0.510 \pm 0.030$ & $21.4 \pm 3.9$ \\
\hline Benzo(a)pyrene & $1.17 \pm 0.09^{\mathrm{a})}$ & $0.260 \pm 0.020$ & $22.6 \pm 6.8$ \\
\hline Dibenzo(a,h)anthracene & $0.365 \pm 0.071^{\mathrm{a})}$ & $0.220 \pm 0.020$ & $61.1 \pm 7.3$ \\
\hline Benzo(g,h,i)perylene & $5.91 \pm 0.18^{\mathrm{a})}$ & $1.03 \pm 0.07$ & $17.4 \pm 5.3$ \\
\hline Indeno( $1,2,3$-cd)pyrene & $4.44 \pm 0.28^{\mathrm{a})}$ & $0.690 \pm 0.020$ & $15.5 \pm 2.3$ \\
\hline
\end{tabular}

a) Certified values.

b) Reference values. 


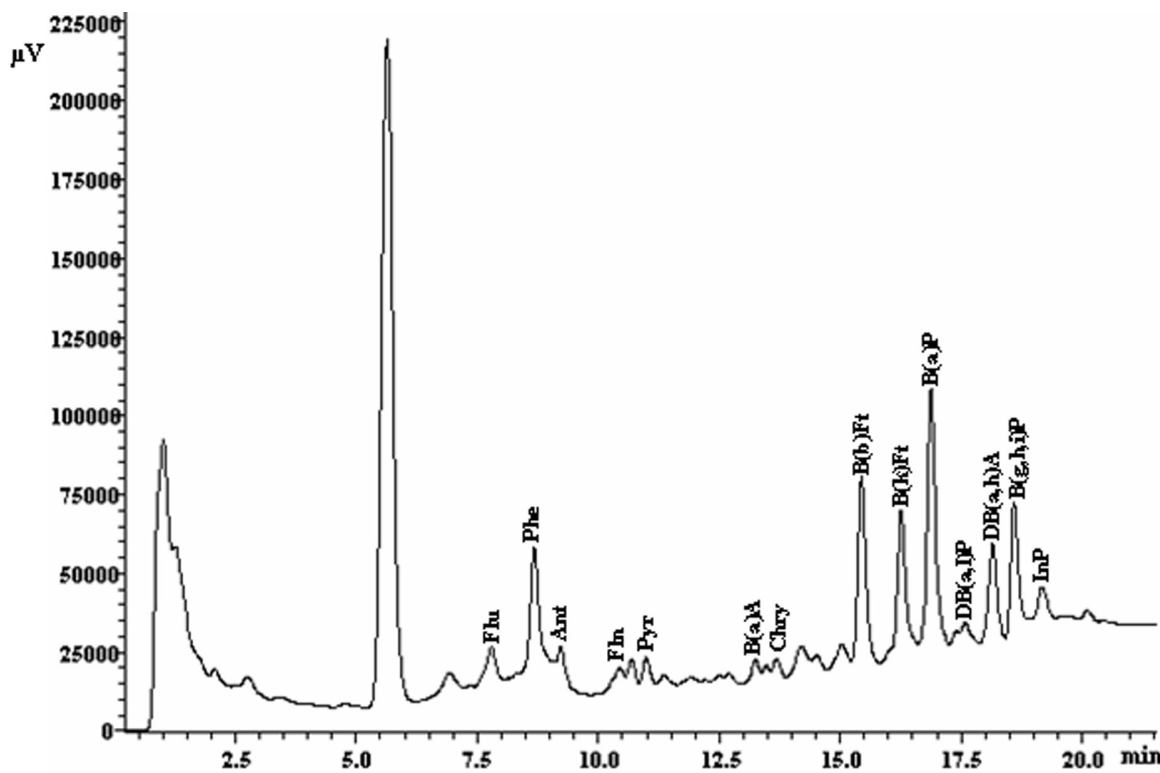

Figure 3. LC-FLD chromatogram of a $\mathrm{PM}_{10}$ sample collected in the city of Oporto.

dure. Referring to the other analyzed PAHs, except for dibenzo(a,h)anthracene, a drastic reduction in the extraction efficiency was observed and all yields are lower than 23\%. These results are in accordance with those reported by Piñeiro et al. [16] for the same SRM. These authors tested also the SRM 1648 "Urban particulate matter" (actually no SRM of natural atmospheric PM is available) and concluded that the nature of SRM 1650b was quite different from real atmospheric particulate samples, because this diminution effect was not appreciated for SRM 1648 and real atmospheric PM [16]. Regarding the repeatability of the optimized methodology, expressed as RSD, values were lower than $13 \%$.

\subsection{Application to outdoor PM samples collected in Oporto}

The developed analytical protocol was applied for the quality control of outdoor PM samples $\left(\mathrm{PM}_{2.5}\right.$ and $\left.\mathrm{PM}_{10}\right)$. The monitoring campaign was from 17-25 of February 2008 (for a period of nine consecutive days), in a site directly influenced by traffic emissions in the city of Oporto (north of Portugal).

Particulate PAHs concentrations are summarized in Table 6 and a representative chromatogram is shown in Fig. 3. The average value for each compound, with the minimum and maximum values and the total PAHs concentrations (sum of the 15 compounds since acenaphthene was not detected) are reported for the 9 days of sampling in $\mathrm{PM}_{2.5}$ and $\mathrm{PM}_{10}$. Results are presented in mass of PAH per cubic meter of air. Concentrations of individual compounds are in a range up to $10.5 \mathrm{ng} / \mathrm{m}^{3}$ (dibenzo(a,h)anthracene in $\mathrm{PM}_{2.5}$ ). The most abundant PAHs in $\mathrm{PM}$ samples $\left(\mathrm{PM}_{2.5}\right.$ and $\left.\mathrm{PM}_{10}\right)$ during the campaign were, by descending order: dibenzo(a,h)anthracene (ca. 40\% of total PAHs), indeno(1,2,3-cd)pyrene (ca. 10\%), benzo(b)fluoranthene (ca. 9\%), benzo(g,h,i)perylene (ca. 8\%), and benzo(a)pyrene (ca. 7\%). The sum of particulate-bound PAHs in outdoor PM ranged from 2.5 to $28 \mathrm{ng} / \mathrm{m}^{3}$.

Because PAHs are generally considered as typical products of incomplete combustion of organic matter, the increased concentrations in atmospheric particulate samples are readily associated to the intense traffic which takes place during working days. During the period under study, and in the site where the sampling was done, the average level of benzo(a)pyrene in $\mathrm{PM}_{10}$ was above the legal limit in $\mathrm{EU}\left(1 \mathrm{ng} / \mathrm{m}^{3}\right)$ [1] which is a worrying factor. Also, the detection of dibenzo(a,1)pyrene, despite the low levels determined, is of special interest since it is considered one of the most carcinogenic [8].

The mean concentrations of almost the individual PAHs and consequently the total PAHs $\left(\Sigma_{\mathrm{PAH}}\right)$ at the traffic site were similar for both $\mathrm{PM}_{2.5}$ and $\mathrm{PM}_{10}$ fractions. Therefore, it was concluded that the PAHs were mainly present in fine fractions. This fact supports the importance to monitor this fraction in order to better understand $\mathrm{PM}_{2.5}$ impacts to consequently develop appropriate policies to protect public health.

\section{Conclusions}

It can be stated that MAE provides a fast, simple, and efficient procedure for the extraction of PAHs from real atmospheric particulate samples $\left(\mathrm{PM}_{2.5}\right.$ and $\mathrm{PM}_{10}$, the size of PM did not influence the efficiency of the extraction) with a low consumption of toxic solvents and environmental burden, nowadays two crucial parameters in the choice of the extraction technique. Considering the 
Table 6. Average concentrations of PAHs $(n=3)$ measured in outdoor $\mathrm{PM}_{2.5}$ and $\mathrm{PM}_{10}$ samples collected in the city of Oporto (Portugal, traffic site) during a period of nine consecutive days

\begin{tabular}{|c|c|c|c|c|}
\hline \multirow[t]{2}{*}{ Compound } & \multicolumn{2}{|c|}{ Mean concentration $\pm \mathrm{SD}\left(\mathrm{ng} / \mathrm{m}^{3}\right)$} & \multicolumn{2}{|c|}{$\operatorname{Min}-\max \left(\mathrm{ng} / \mathrm{m}^{3}\right)$} \\
\hline & $\mathrm{PM}_{2.5}$ & $\mathrm{PM}_{10}$ & $\mathrm{PM}_{2.5}$ & $\mathrm{PM}_{10}$ \\
\hline Naphthalene & $0.0372 \pm 0.0420$ & $0.0339 \pm 0.0360$ & $0.000-0.0910$ & $0.000-0.1000$ \\
\hline Acenaphthene & n.d. & n.d. & n.d. & n.d. \\
\hline Fluorene & $0.0435 \pm 0.035$ & $0.0573 \pm 0.036$ & $0.00400-0.108$ & $0.0070-0.0950$ \\
\hline Phenanthrene & $0.435 \pm 0.31$ & $0.505 \pm 0.39$ & $0.0330-0.891$ & $0.0870-1.290$ \\
\hline Anthracene & $0.343 \pm 0.25$ & $0.341 \pm 0.32$ & $0.0610-0.793$ & $0.0530-0.975$ \\
\hline Fluoranthene & $0.144 \pm 0.110$ & $0.165 \pm 0.16$ & $0.008-0.321$ & $0.0230-0.408$ \\
\hline Pyrene & $0.476 \pm 0.330$ & $0.636 \pm 0.42$ & $0.061-1.000$ & $0.0850-1.23$ \\
\hline Benzo(a)anthracene & $0.695 \pm 0.490$ & $0.687 \pm 0.50$ & $0.0820-1.35$ & $0.0730-1.38$ \\
\hline Chrysene & $0.870 \pm 0.580$ & $0.905 \pm 0.62$ & $0.0960-1.64$ & $0.106-1.84$ \\
\hline Benzo(b)fluoranthene & $1.63 \pm 0.88$ & $1.58 \pm 0.91$ & $0.250-2.93$ & $0.262-2.98$ \\
\hline Benzo(k)fluoranthene & $0.599 \pm 0.33$ & $0.582 \pm 0.34$ & $0.0960-1.11$ & $0.102-1.16$ \\
\hline Benzo(a)pyrene & $1.23 \pm 0.67$ & $1.16 \pm 0.67$ & $0.194-2.16$ & $0.198-1.99$ \\
\hline Dibenzo(a,1)pyrene & $0.0158 \pm 0.0130$ & $0.0198 \pm 0.022$ & $0.002-0.0400$ & $0.0020-0.0700$ \\
\hline Dibenzo(a,h)anthracene & $6.68 \pm 2.90$ & $6.17 \pm 2.9$ & $0.946-10.5$ & $1.07-9.64$ \\
\hline Benzo(g,h,i)perylene & $1.45 \pm 0.70$ & $1.41 \pm 0.72$ & $0.298-2.31$ & $0.311-2.39$ \\
\hline Indeno(1,2,3-cd)pyrene & $1.69 \pm 0.76$ & $1.62 \pm 0.79$ & $0.366-2.58$ & $0.358-2.83$ \\
\hline इPAHs & $16.3 \pm 8.0$ & $15.9 \pm 8.4$ & $2.51-26.2$ & $2.79-27.9$ \\
\hline
\end{tabular}

n, Number of samples; n.d., not detected.

value established in the EC Directive [1], sufficiently low LOQs were obtained which allow the method to be used for monitoring purposes with reduced sampling time (12-24 h). Smaller sample sizes become important when dealing with real life problems, such as alleged contamination, consumer complaints, and safety risk assessments. Also, and since losses of PAHs from PM collected on filters are more significant for the compounds containing less than five rings when the sampling time exceeds $24 \mathrm{~h}$ [39], the concentrations reported will be a good estimation of the environmental levels. The toxicity of PAHs justifies the need to establish their content in urban PM.

This work was supported by Fundação Calouste Gulbenkian. D. Castro thanks the Fundação para Ciência e para a Tecnologia (FCT) for her PhD fellowship (SFRH/BD/23605/2005).

The authors declared no conflict of interest.

\section{References}

[1] EC Directive 2004, 2004/107/EC of the European Parliament and of the Council relating to arsenic, cadmium, mercury, nickel and polycyclic aromatic hydrocarbons in ambient air, Official Journal of the European Union L23, 3-16.

[2] WHO, World Health Organisation, Environmental Health Criteria 202: Selected nonheterocyclic polycyclic aromatic hydrocarbons, IPCS, International Programme on Chemical Safety, World Health Organisation, Geneva 1998.

[3] Mastral, A. M., Callen, M. S., Environ. Sci. Technol. 2000, 34, 3051 3057.
[4] Zhang, X. L., Tao, S., Liu, W. X., Yang, Y., Zuo, Q., Liu, S. Z., Environ. Sci. Technol. 2005, 39, 9109-9114.

[5] Srogi, K., Environ. Chem. Lett. 2007, 5, 169-195.

[6] Brunekreef, B., Holgate, S. T., Lancet 2002, 360, 1233-1242.

[7] Ravindra, K., Mittal, A., Gieken, R. V., Rev. Environ. Health 2001, 16, 169-189.

[8] Pufelete, M., Battershill, J., Boobis, A., Fielder, R., Regul. Toxicol. Pharm. 2004, 40, 54-66.

[9] Okona-Mensah, K. B., Battershill, J., Boobis, A., Fielder, R., Food Chem. Toxicol. 2005, 43, 1103-116.

[10] Kameda, Y., Shirai, J., Komai, T., Nakanishi, J., Masunaga, S., Sci. Total Environ. 2005, 340, 71-80.

[11] Pleil, J. D., Vette, A. F., Rappaport, M., J. Chromatogr. A 2004, 1033, 9-17.

[12] Gambaro, A., Manodori, L., Moret, I., Capodaglio, G., Cescon, P., Anal. Bioanal. Chem. 2004, 378, 1806-1814.

[13] Bélanger, J. M. R., Jocelyn Pare, J. R., Anal. Bioanal. Chem. 2006, 386, 1049-1058.

[14] Song, J.-Z., Mo, S.-F., Yip, Y.-K., Qiao, C.-F., Han, Q.-B., Xu, H.-X., J. Sep. Sci. 2007, 30, 819-824.

[15] Srogi, K., Anal. Lett. 2006, 39, 1261-1288.

[16] Piñeiro-Iglesias, M., López-Mahía, P., Vásquez-Blanco, E., Muniategui-Lorenz, S., Prada-Rodríguez, D., Fernández-Fernández, E., J. Anal. Chem. 2000, 367, 29-34.

[17] Piñeiro-Iglesias, M., López-Mahía, P., Muniategui-Lorenzo, S., Prada-Rodríguez, D., Querol, X., Alastuey, A., Atmos. Environ. 2003, 37, 4171-4175.

[18] Piñeiro-Iglesias, M., Grueiro-Noche, G., López-Mahía, P., Muniategui-Lorenzo, S., Prada-Rodríguez, D., Sci. Total Environ. 2004, 334, $377-384$.

[19] Karthikeyan, S., Balasubramanian, R., See, S. W., Talanta 2006, 69, $79-86$.

[20] Slezakova, K., Pereira, M. C., Reis, M. A., Alvim-Ferraz, M. C., J. Atmos. Chem. 2007, 58, 55-68.

[21] Miller, J. N., Miller, J. C., Statistics for Analytical Chemistry, 4th edition, Harlow: Pearson Education Limit, London 2000.

[22] Gfrerer, M., Lankmayr, E., Anal. Chim. Acta 2005, 533, 203-211. 
[23] Tomaniova, M., Hajslova, J., Pavelka, J. J., Kocourck, V., Holadova, K., Klimova, I., J. Chromatogr. A 1998, 827, 21 - 29.

[24] Chee, K. K., Wong, M. K., Lee, H. K., Anal. Chim. Acta 1996, 330, 217- 227

[25] Villar, P., Callejón, M., Alonso, E., Jiménez, J. C., Guiraum, A., Anal. Chim. Acta 2004, 524, 295-304.

[26] Hien, T. T., Nam, P. P., Yasuhiro, S., Takayuki, K., Norimichi, T., Hiroshi, B., Sci. Total Environ. 2007, 382, 70-81.

[27] Nakajima, D., Goto, S., Sugita, K., Ohkubo, T., Endo, O., Yajima, H., Ishii, T., Polycyclic Aromat. Compd. 2004, 24, 647-656.

[28] Dallarosa, J. B., Teixeira, E. C., Pires, M., Fachel, J., Atmos. Environ. 2005, 39, 6587-6596.

[29] Possanzini, M., Palo, V. D., Gigliucci, P., Scianó, M. C. T., Cecinato, A., Atmos. Environ. 2004, 38, 1727-1734.

[30] Portet-koltalo, F., Oukebdance, K., Dionnet, F., Desbène, P. L., Anal. Bioanal. Chem. 2008, 390, 389-398.
[31] Dean, J. R., Xiong, G., Trends Anal. Chem. 2000, 19, 553-564.

[32] Teixeira, V. H., Casal, S., Oliveira, M. B. P. P., Food Chem. 2007, 104 106-112.

[33] Richardi, J., Krienke, H., Mol. Phys. 1997, 90, 841-853.

[34] Mackay, D., Shiu, W. Y., J. Chem. Eng. Data 1977, 22, 399.

[35] Sun, Y., Takaoka, M., Takeda, N., Matsumoto, T., Oshita, K., J. Sep. Sci. 2005, 28, 585-588.

[36] Li, K., Li, H., Liu, L., Hashi, Y., Maeda, T., Lin, J.-M., J. Chromatogr. A 2007, 1154, 74-80.

[37] Borrás, E., Tortajada-Genaro, L. A., Anal. Chim. Acta 2007, 583, 266-276.

[38] Hollander, M., Wolfe, D., Nonparametric Statistical Methods, 2nd edition, John Wiley and Sons, New York 1999.

[39] Peltonen, K., Kuljukka, T., J. Chromatogr. A 1995, 710, 93-108. 